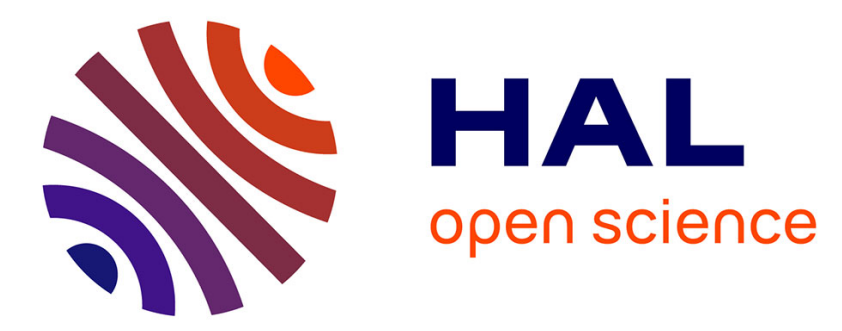

\title{
Modeling the Surface Energy Budget during the Thawing Period of the 2006 Montreal Urban Snow Experiment
}

Sylvie Leroyer, Jocelyn Mailhot, Stéphane Bélair, Aude Lemonsu, Ian B Strachan

\section{To cite this version:}

Sylvie Leroyer, Jocelyn Mailhot, Stéphane Bélair, Aude Lemonsu, Ian B Strachan. Modeling the Surface Energy Budget during the Thawing Period of the 2006 Montreal Urban Snow Experiment. Journal of Applied Meteorology and Climatology, 2010, 49 (1), pp.68-84. 10.1175/2009JAMC2153.1. hal-02369025

\section{HAL Id: hal-02369025 \\ https://hal.science/hal-02369025}

Submitted on 18 Nov 2019

HAL is a multi-disciplinary open access archive for the deposit and dissemination of scientific research documents, whether they are published or not. The documents may come from teaching and research institutions in France or abroad, or from public or private research centers.
L'archive ouverte pluridisciplinaire HAL, est destinée au dépôt et à la diffusion de documents scientifiques de niveau recherche, publiés ou non, émanant des établissements d'enseignement et de recherche français ou étrangers, des laboratoires publics ou privés. 


\title{
Modeling the Surface Energy Budget during the Thawing Period of the 2006 Montreal Urban Snow Experiment
}

\author{
SYLVIE LEROYER \\ Atmospheric and Environmental Research Laboratory, McGill University, Ste-Anne-de-Bellevue, Quebec, Canada \\ JOCELYN MAILHOT AND STÉPHANE BÉLAIR \\ Meteorological Research Division, Environment Canada, Dorval, Quebec, Canada \\ Aude Lemonsu \\ Centre National De Recherches Météorologiques, Toulouse, France \\ IAN B. STRACHAN \\ Department of Natural Resource Sciences, McGill University, Ste-Anne-de-Bellevue, Quebec, Canada
}

(Manuscript received 10 November 2008, in final form 11 June 2009)

\begin{abstract}
The Montreal Urban Snow Experiment was dedicated to furthering the understanding of micrometeorological processes involved in the late winter-early spring transition period in a Canadian city. A surface energy budget (SEB) measurement site was installed in a dense residential area of Montreal for several weeks in 2005 and 2006. This paper focuses on the last 6 days of the 2006 experiment (23-28 March 2006), after snowmelt and before vegetation became active, with the objectives of providing a better understanding of physical processes involved during this transition period and examining their impact on the SEB. The Town Energy Balance urban canopy model and the Interactions between Soil, Biosphere, and Atmosphere force-restore land surface model are used in stand-alone mode and are forced with meteorological data measured at the top of a 20-m AGL instrumented tower. Preliminary results reveal deficiencies in the models' ability to simulate the surface energy budget partitioning, and in particular show overestimation of the sensible heat flux. Sensitivity studies indicate that a large portion of these problems is related to the latent heat transfer involved in natural soil freeze/thaw processes, which has a significant effect on the surface energy budget in this urban area. It is also found that the SEB in this particular situation is very sensitive to the thermal roughness length used for local energy exchange over the roof and road surfaces.
\end{abstract}

\section{Introduction}

Accurate estimation of the urban surface energy budget (SEB) is of great importance for atmospheric modeling in urban areas, as physical processes occurring in the surface layer largely influence the urban boundary layer development and are responsible for urban heat islands (Oke 1982). The complex three-dimensional arrangement of cities, which typically includes various types of

Corresponding author address: Dr. Sylvie Leroyer, Meteorological Research Branch, Environment Canada, 2121 TransCanada Highway, Dorval, QC H9P 1J3, Canada.

E-mail: sylvie.leroyer@ec.gc.ca surfaces and obstacles (e.g., buildings, paved surfaces, as well as natural covers including soil, grass, and trees), represents an enormous challenge to the numerical modeling of the SEB.

The most commonly used methods to provide lower boundary conditions over urban areas for atmospheric models are based on urban canopy models (Masson 2000; Kusaka et al. 2001; Kondo et al. 2005; Lee and Park 2008), or on more simplified surface schemes (De Ridder and Schayes 1997; Dupont and Mestayer 2006). Some models also directly resolve the flow inside the canopy, independently from the atmospheric model (Hamdi and Masson 2008) or as a module integrated with it (Martilli et al. 2002; Dupont et al. 2004). In general, 
these models are able to reproduce the main features of the urban SEB, such as the phase lag between the different fluxes with respect to the net radiation. The resulting asymmetric surface energy budget typically observed during daytime in urban areas is due to shadowing effects and radiative trapping within the canyon-like geometry (Oke et al. 1999; Grimmond and Oke 1999a).

Field campaigns (including in North America: Grimmond and Oke 1995; Oke et al. 1999; Grimmond and Oke 1999a; in Europe: Mestayer et al. 2005; Rotach et al. 2005; Offerle et al. 2006; in Africa: Offerle et al. 2005; and in Asia: Moriwaki and Kanda 2004) in various cities and climatic conditions have expanded our knowledge of the urban SEB and helped in the evaluation of urban models (Masson et al. 2002; Lemonsu et al. 2004; Roulet et al. 2005; Dupont and Mestayer 2006; Hamdi and Schayes 2007; Lee and Park 2008; Leroyer et al. 2010).

Recently, such a study, called the Montreal Urban Snow Experiment (MUSE), was conducted to examine the surface energy budget during eastern Canada's late winter and early spring (Bélair et al. 2006; Lemonsu et al. 2008). Using similar protocols, the MUSE observational configuration was deployed during two consecutive winters (2005 and 2006) in a dense residential district of Montreal, Canada. The first results of the 2005 experiment (Lemonsu et al. 2008) revealed the importance to the SEB of snow melting through the significant latent heat required to melt large amounts of snow. It was found that the energy budgets in the presence of snow did not display any phase lag between the different fluxes, compared with the more asymmetric budgets found for the period after snowmelt.

A more recent study by Lemonsu et al. (2010) examined the ability of the Town Energy Balance canopy model (TEB; Masson 2000; Masson et al. 2002) and the Interactions between Soil, Biosphere, and Atmosphere surface model (ISBA; Noilhan and Planton 1989) to simulate the urban micrometeorology during the MUSE2005 experiment for periods with and without snow. Results obtained for the snowy environment were in fair agreement with measurements, and the evolution of the urban snowpacks was shown to be well simulated. Some questions remained, however, concerning the SEB for days following the snowmelt, when unexpected and persistent low values of the sensible heat flux were still observed, and when important discrepancies between the models' results and observations were noted.

Our main objectives in this paper are thus to correctly represent the surface energy budget during this transition period (after snowmelt and before vegetation becomes active) and to examine the sensitivity of this energy budget to specific physical processes. In the next section, the MUSE-2006 experiment, which provides observational data for this study, is described. It is followed in section 3 by a description of the modeling tools and of the experimental setup. Results for the control experiment are described in section 4, together with the elaboration of working hypotheses. Results from two sensitivity experiments are discussed in sections 5 and 6 , which are followed by a summary and conclusions in section 7 .

\section{The Montreal Urban Snow Experiment 2006}

The MUSE program was set up in 2005 and 2006 to study the evolution of the surface characteristics and energy exchanges between the surface and the atmosphere in an urban environment characterized by cold and snowy conditions, and to evaluate the new numerical tools for urban modeling recently developed at the Meteorological Service of Canada (MSC; see section 3). Two consecutive winters were documented: the first part of MUSE took place from 17 March to 14 April 2005, and the second part from 7 February to 29 March 2006, with energy budget sites located in the Montreal dense residential district of Rosemont-Petite-Patrie.

As can be seen in Fig. 1, the district where measurements were taken is quite homogeneous, with arrays of blocks mostly oriented southeast-northwest. Those elements form two different street canyons that feature residential houses of two or three stories (the mean building height is about $9.5 \mathrm{~m}$ ). As is often the case in North American cities such as Montreal, there are essentially two types of canyon in this part of the urban area. The first type is characterized by a two-lane paved road where traffic flows, with car parking along the sides of the roadway, sidewalks, and regular arrays of trees, and with small front yards mostly covered by grass (this type is hereinafter referred to as STREET canyons). The second type includes a narrow paved access road for residents (with substantially less traffic), small backyards with grass cover, paved paths connecting houses to the road, and sometimes paved parking spots (this type is hereinafter referred to as ALLEY canyons). For technical reasons, the site used for MUSE-2006 was different from the one used for MUSE-2005 described in Lemonsu et al. (2008). Nevertheless, both sites are very close (about $500 \mathrm{~m}$ away) and have nearly identical characteristics.

Measurements in MUSE-2006 were made according to the same protocol as in MUSE-2005 (Lemonsu et al. 2008). The instrumentation and position of the sensors for MUSE-2006 are summarized in Table 1. The main element of the site was a 20-m above ground level (AGL) tower upon which all the instrumentation required to document the surface energy budget was installed. The tower was located in a private backyard of Marquette 


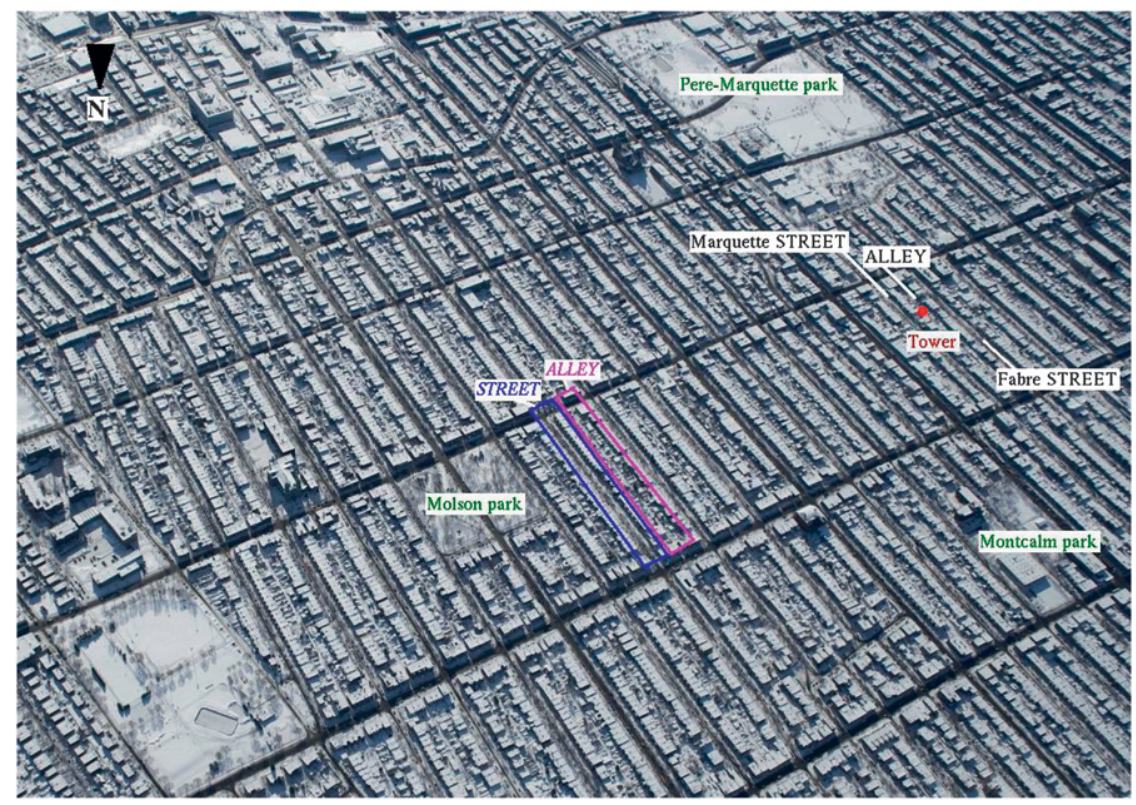

FIG. 1. Aerial photograph of the Montreal Rosemont-Petite-Patrie district. The locations of the MUSE-2006 measurement tower and the surroundings parks are indicated. An example of the STREET and ALLEY canyon samples representing the residential area is delimited by the blue and purple lines [the photograph was taken on $28 \mathrm{Feb} 2008$, in the framework of the EPiCC program (http://www.epicc.uwo.ca/), and is provided through the courtesy of J. Voogt at The University of Western Ontario].

Street (as seen in Fig. 1) and had sensors at different heights to measure meteorological variables. In contrast with the MUSE-2005 experiment, however, in which intensive observing periods (IOPs) included manual measurements of temperatures for different surface types (i.e., roofs, walls, and roads), these measurements were automatically done in MUSE-2006 using thermal radiative sensors operating in a continuous mode. In addition, an infrared camera was mounted at the top of the tower, providing thermal images that were used to obtain spatially averaged surface temperatures of walls, roads, and roofs. Net radiation and snow depth were automatically measured on the roof closest to the tower. It is worth noting that the thermal images did not reveal strong differences between this particular roof and adjacent roofs. A Webcam installed on the same roof took pictures of the Marquette Street canyon during the last two weeks of the experiment. In 2006, manual measurements were done only for snow depth and albedo on the road parts of the STREET and ALLEY canyons.

The top of the tower was about twice as high as the mean building height in order to have measurements of the turbulent fluxes in the inertial sublayer and avoid local effects associated with individual roughness elements (Roth 2000; Arnfield 2003; Grimmond 2006; Oke 2007). The 30 -min average sensible $\left(Q_{H}\right)$ and latent $\left(Q_{E}\right)$ heat fluxes were obtained by the eddy covariance technique (Baldocchi 2003) using a three-axis sonic anemometer and an open-path infrared gas analyzer. For the instrument used in this study (i.e., net radiometer model CSAT3 from Campbell Scientific, Inc.; Table 1) the measurement error has been evaluated as $5 \%$ for the sensible heat flux and $10 \%$ for the latent heat flux (Mauder et al. 2006). The net radiative flux (also called the net radiation) $Q^{*}$ can be written as

$$
Q^{*}=S_{\downarrow}-S_{\uparrow}+L_{\downarrow}-L_{\uparrow},
$$

where $S_{\downarrow}$ and $L_{\downarrow}$ are the incoming solar and longwave radiative fluxes, respectively, $S_{\uparrow}$ is the reflected solar radiative flux, and $L_{\uparrow}$ is the longwave radiative flux emitted upward. Kohsiek et al. (2007) found that measurements of $Q^{*}$ have an accuracy of about $20 \mathrm{~W} \mathrm{~m}^{-2}$ using the net radiometer model CNR1 from Kipp and Zonen, Inc., as in MUSE-2006 (Table 1). The radiative budget can also be written in terms of the complete surface temperature $\left[T_{S}\right.$, as defined by Voogt and Oke (1997)], the composite surface albedo $(\alpha)$, and emissivity $(\varepsilon)$ as

$$
Q^{*}=S_{\downarrow}(1-\alpha)+\varepsilon\left(L_{\downarrow}-\sigma T_{S}^{4}\right),
$$

where $\sigma$ is the Stefan-Boltzmann constant. It is possible to adapt Eq. (2) for each individual facet of the urban elements. A part of this energy is converted into turbulent 
TABLE 1. Summary of automatic measurements in MUSE-2006; $z_{h}$ is the height AGL. The front wall of the main house is a northeastoriented wall and is a part of the STREET canyon. The back wall is a southwest-oriented wall and is a part of the canyon ALLEY.

\begin{tabular}{|c|c|c|c|c|}
\hline & Variables & Sensor and model & $z_{h}(\mathrm{~m})$ & Location \\
\hline \multirow[t]{4}{*}{ Fluxes } & Radiations & Four-component radiometer, CNR1 & 20.1 & Tower \\
\hline & $u, v, w, u_{*}$ & 3D sonic anemometer, CSAT3 & 20.7 & \\
\hline & $\theta^{\prime} q^{\prime}$ & Thermocouple, ASPTC (10 Hz) & 19.8 & \\
\hline & {$\left[\mathrm{H}_{2} \mathrm{O}\right],\left[\mathrm{CO}_{2}\right]$} & Open-path gas analyzer, Li-Cor, Inc., LI-7500 & 20.7 & \\
\hline \multirow[t]{2}{*}{ Meteorological } & $\begin{array}{l}\text { Air temperature, } \\
\text { humidity }\end{array}$ & HMP $45 \mathrm{C}$ & 19.8 & Tower \\
\hline & Wind & RM Young 05-305 & 21.3 & \\
\hline \multirow[t]{2}{*}{ Canyon } & $\begin{array}{l}\text { Air temperature, } \\
\text { air humidity }\end{array}$ & HMP45C & 3.9 & $\begin{array}{l}\text { Marquette Street, balcony, } \\
3.7 \mathrm{~m} \text { from the front wall }\end{array}$ \\
\hline & & & 3.7 & $\begin{array}{l}\text { ALLEY canyon, } 12.6 \mathrm{~m} \text { away } \\
\text { from the back wall }\end{array}$ \\
\hline \multirow[t]{3}{*}{ Roof } & Radiative fluxes & CNR1 & 1.5 & Middle of the roof \\
\hline & Snow depth & SR50 & & \\
\hline & Surface temperature & Thermovision A40M & 19.8 & Tower top, direction controlled \\
\hline \multirow[t]{7}{*}{ Wall } & Surface temperature & Ray MI & 3.9 & $\begin{array}{l}3.7 \mathrm{~m} \text { from the front wall, pointing } \\
\text { toward the NE-oriented wall }\end{array}$ \\
\hline & & & 3.9 & $\begin{array}{l}3.7 \mathrm{~m} \text { from the front wall, pointing } \\
\text { toward the } \mathrm{SW} \text {-oriented wall }\end{array}$ \\
\hline & & & 3.7 & $\begin{array}{l}12.6 \mathrm{~m} \text { from the back wall, pointing } \\
\text { toward the NE-oriented wall }\end{array}$ \\
\hline & & & 3.7 & $\begin{array}{l}12.6 \mathrm{~m} \text { from the back wall, pointing } \\
\text { toward the } \mathrm{SW} \text {-oriented wall }\end{array}$ \\
\hline & & & 1.7 & $\begin{array}{l}3.55 \mathrm{~m} \text { from the sidewall, pointing } \\
\text { toward the SE-oriented wall }\end{array}$ \\
\hline & & & 1.7 & $\begin{array}{l}3.85 \mathrm{~m} \text { from the sidewall, pointing } \\
\text { toward the } \mathrm{NW} \text {-oriented wall }\end{array}$ \\
\hline & & Thermovision A40M & 19.8 & Tower top, direction controlled \\
\hline \multirow[t]{3}{*}{ Road } & Surface temperature & Ray MI & 3.9 & $\begin{array}{l}\text { Marquette Street, balcony, } \\
3.7 \mathrm{~m} \text { from the front wall }\end{array}$ \\
\hline & & & 3.7 & $\begin{array}{l}\text { ALLEY canyon, } 12.6 \mathrm{~m} \text { from } \\
\text { the back wall }\end{array}$ \\
\hline & & Thermovision A40M & 19.8 & Tower top, direction controlled \\
\hline Natural & Surface temperature & Ray MI & 3.7 & $\begin{array}{l}\text { ALLEY canyon, grassland, } 12.6 \mathrm{~m} \\
\text { from the back wall }\end{array}$ \\
\hline
\end{tabular}

fluxes, and the surface energy budget closure equation at the measurement height can thus be expressed using a residual term $Q_{\text {res }}$ as follows:

$$
Q^{*}=Q_{H}+Q_{E}+Q_{\text {res }} \text {. }
$$

In the absence of snow, the residual term $\left(Q_{\text {res }}\right)$ represents the contribution of the storage heat flux into the canopy $\left(\Delta Q_{S}\right)$, the anthropogenic heat flux $\left(Q_{F}\right)$, and the net advective heat flux $\left(\Delta Q_{A}\right)$ so that $Q_{\text {res }}=\Delta Q_{S}+$ $\Delta Q_{A}-Q_{F}$. More specifically, the term $\Delta Q_{S}$ contains the heat stored in buildings, into artificial and natural grounds, and into the canopy air layer. The anthropogenic heat flux, $Q_{F}$, represents the heat released by traffic vehicles and industries and the energy consumption for space heating. The advective heat flux term $\Delta Q_{A}$ should be negligible in the horizontally homogeneous environment of MUSE.

In his review of over 20 years of research on surface energy balance closures, Foken (2008) argued that im- balances between radiative and turbulent components often observed in past experiments over land surfaces are likely attributable to the scale considered. Some experimental and modeling studies (e.g., Beyrich et al. 2006; Kanda et al. 2004) have suggested that the influence of large-scale eddies on turbulent fluxes (in addition to that from the small eddy fluctuations) may be at least partially responsible for an underestimation of turbulent fluxes measured by the eddy covariance method. Current observational studies lack the ability to account for such scale-generated underestimation of the turbulent fluxes within the surface energy balance.

The residual term is influenced by any observational errors from the other terms of the SEB (Oke et al. 1999; Grimmond and Oke 1999a; Kanda 2007). For instance, the possible underestimation of turbulent fluxes associated with the eddy covariance method may induce an overestimation of the residual term. Another potential source of errors is related to unequal footprint areas for 
the radiative and turbulent fluxes. Indeed, the radiative footprint area is fixed, and is different from the turbulent flux footprint, which varies depending on wind speed, roughness length, and atmospheric stability (Schmid et al. 1991).

\section{Modeling tool and experimental setup}

A new urban modeling system has been developed at MSC (Mailhot et al. 2006) for research purposes and for near-future implementation within its operational activities. In this system, surface schemes are used to define the lower boundary conditions of the atmospheric model. These boundary conditions are in fact the surface turbulent fluxes obtained from Monin-Obukhov similarity theory (MOST), taking into account static stability. Each urbanized model cell is split into two distinct surface types: a built-up area, represented with TEB (Masson 2000; Masson et al. 2002), and a natural surface area described by the force-restore ISBA model originally developed by Noilhan and Planton (1989) and implemented with some modifications in the Canadian regional and global operational weather forecast system (Bélair et al. 2003a,b). The effective surface fluxes provided to the atmospheric vertical diffusion scheme are thus a linear combination of both urban and natural sources, based on the fraction of built-up and natural surfaces.

TEB is a single-layer canopy model for which the built-up area is composed of a roof area and a street canyon, and includes the air volume within. The energy budget of the three impervious surface types (roof, road, and wall) is resolved individually. The shadowing effects and radiative trapping in the canyon are taken into account in the radiative energy budget, considering isotropic street orientations. Thermal diffusion into the artificial materials is then considered using thermal properties and thicknesses of the specified layers (three in this study). The momentum flux is calculated for the whole canopy, whereas thermal and hydrological fluxes for built-up areas are computed using an aerodynamic resistances network that considers local energy exchange within and above the canyon [see Masson (2000) for the original resistances network and Masson et al. (2002); Lemonsu et al. (2004) for further updates].

The land use and canyon morphology of the considered area are determined using orthophotographs obtained from the Navigateur Urbain of the City of Montreal (http://www.navurb.com/). An example of the regular arrangement of the samples of STREET and ALLEY canyons that are defined for this study is given in Fig. 1. Details of the urban cover types and structures (following the definition of Oke 2006) for those two
TABLE 2. Fractional coverage of urban cover type [cover fraction of natural, road (i.e., paved area), and roof surfaces] and corresponding structural features (mean building height $z_{H}$, canyon aspect ratio $z_{H} / w$, with $w$ as the mean distance between the buildings; frontal aspect ratio $\alpha_{F}=A_{\text {wall }} / A_{\text {plan }}$ with $A_{\text {wall }}$ as the wall surface and $A_{\text {plan }}$ as the total horizontal surface; the plane area density $\alpha_{P}=A_{\text {roof }} / A_{\text {plan }}$ with $A_{\text {roof }}$ as the roof surface; canopy aerodynamic roughness $z_{0 \mathrm{~m}}$ ) of the STREET and ALLEY canyons (with their respective fraction in the cell aggregation).

\begin{tabular}{lccccccccc}
\hline \hline & Natural & Road & Roof & $z_{H}$ & $z_{H} / w$ & $\alpha_{F}$ & $\alpha_{P}$ & $z_{0 \mathrm{~m}}$ \\
Canyon type & - & - & - & $\mathrm{m}$ & - & - & - & $\mathrm{m}$ \\
\hline STREET (0.51) & 0.15 & 0.50 & 0.35 & 9.5 & 0.37 & 0.48 & 0.35 & 1.24 \\
ALLEY (0.49) & 0.29 & 0.37 & 0.34 & 9.5 & 0.34 & 0.45 & 0.34 & 1.24 \\
\hline
\end{tabular}

different canyons are specified by considering four samples around the tower (Table 2). The resulting whole urban district sample is composed of $22 \%$ natural cover and $78 \%$ built-up surfaces. In Table 2 , the aerodynamic roughness length was found using the plan area density and Fig. 1 of Grimmond and Oke (1999b).

The study period is the last 6 days of the 2006 field experiment, from 23 to 28 March (hereinafter referred to as yeardays $82-87$ ). This period followed a cold spell of 8 days during which temperatures were below $0^{\circ} \mathrm{C}$. The period started several hours after the last episode of snow and rainfall that was documented during the experiment. During these six days, the air temperatures measured at the top of the tower were always above $0^{\circ} \mathrm{C}$, except early in the morning on days 82,86 , and 87 . Pictures taken during the experiment show that all surfaces were nearly snow free and that only small residual snowpacks were present in the area.

Stand-alone simulations were carried out using atmospheric forcing obtained with 30-min averaged meteorological measurements at the top of the tower (temperature, specific humidity, incoming solar and longwave radiation, wind speed, and pressure). No precipitation was observed during this period according to measurements made at Montreal's international airport (about $14 \mathrm{~km}$ away from the tower location).

To consider the different effect of the two main canyons, two separate simulations were conducted for the STREET and ALLEY canyons according to the parameters given in Table 2. Results were then aggregated according to the relative area covered by each canyon type. The urban fabric characteristics, that is, the construction and natural materials considered (Oke 2006), are given in Table 3. For built-up surfaces, these characteristics are based on relatively old residential buildings (mostly made of wood, walls covered by bricks, and roofs covered with gravel and tar) and on paved surfaces of asphalt and concrete. Vegetation was not yet active during the study period, as the trees had no leaves. The 
TABLE 3. Urban fabric (radiative and thermal properties of constructions and natural materials; Oke 2006) specified for TEB and ISBA: $\rho c_{p}$ is heat capacity, $\lambda$ is thermal conductivity, $\alpha$ is albedo, $\varepsilon$ is emissivity, and $z_{0 \mathrm{~m}}$ is aerodynamic roughness length of the surface.

\begin{tabular}{|c|c|c|c|c|c|c|c|c|}
\hline \multicolumn{9}{|c|}{ Constructions (for TEB) } \\
\hline & Layer & $\begin{array}{l}\text { Depth } \\
\text { m }\end{array}$ & Material & $\begin{array}{l}\rho c_{p}\left(\times 10^{6}\right) \\
\mathrm{J} \mathrm{K}^{-1} \mathrm{~kg}^{-1}\end{array}$ & $\mathrm{~W} \mathrm{~m}^{\lambda} \stackrel{\lambda}{\mathrm{K}^{-1}}$ & $\alpha$ & $\varepsilon$ & $\begin{array}{c}z_{0 \mathrm{~m}} \\
\mathrm{~m}\end{array}$ \\
\hline \multirow[t]{3}{*}{ Roof } & 1 & 0.05 & Gravel + tar + asphalt & 3 & 1.51 & 0.14 & 0.92 & 0.15 \\
\hline & 2 & 0.4 & Wood & 1.5 & 0.15 & - & - & - \\
\hline & 3 & 0.1 & Insulation + light wood & 0.29 & 0.05 & - & - & - \\
\hline \multirow[t]{3}{*}{ Wall } & 1 & 0.02 & Bricks & 1.55 & 0.934 & 0.35 & 0.9 & - \\
\hline & 2 & 0.125 & Bricks & 1.55 & 0.934 & - & - & - \\
\hline & 3 & 0.05 & Wood & 0.29 & 0.05 & - & - & - \\
\hline \multirow[t]{3}{*}{ Road } & 1 & 0.04 & Asphalt + concrete & 1 & 0.7 & 0.16 & 0.95 & 0.05 \\
\hline & 2 & 0.2 & Soil & 3 & 1.8 & - & - & - \\
\hline & 3 & 1 & Soil & 1.3 & 0.3 & - & - & - \\
\hline
\end{tabular}

Natural materials (for ISBA)

\begin{tabular}{|c|c|c|c|c|c|c|c|c|}
\hline & Layer & $\begin{array}{c}\text { Sand density } \\
-\end{array}$ & $\begin{array}{c}\text { Clay density } \\
-\end{array}$ & $\begin{array}{c}\text { Silt density } \\
-\end{array}$ & $\begin{array}{c}\text { Vegetation fractions } \\
-\end{array}$ & $\begin{array}{c}z_{0 \mathrm{~m}} \\
\mathrm{~m}\end{array}$ & $\begin{array}{l}\alpha \\
-\end{array}$ & $\begin{array}{l}\varepsilon \\
-\end{array}$ \\
\hline \multirow[t]{2}{*}{ Soil } & 1 & 0.19 & 0.50 & 0.31 & 0.67 short grass $/ 0.33$ forbs & 0.015 & 0.2 & 0.9 \\
\hline & 2 & 0.16 & 0.45 & 0.39 & - & - & - & - \\
\hline
\end{tabular}

temperature inside houses was assumed constant (at $20^{\circ} \mathrm{C}$ ) because of temperature control with heating during this cool season. Thus, the anthropogenic source of heat from residential heating is indirectly taken into account in the surface energy budget calculated by TEB by considering heat conduction through the building walls and roofs (as opposed to explicitly having an additional term for $Q_{F}$ defined in section 2). Vehicle traffic releases are the only contribution to $Q_{F}$ directly represented here, since industries (which also contribute to this term in TEB) are not present in the neighborhood of the MUSE observation site. The contribution from traffic in this residential neighborhood is also considered small and is thus neglected in this study.

Because of the problem of the measurement footprint, special care is given to the wind direction and speed when analyzing the data. It is safely assumed that the turbulent footprint's horizontal extension is similar to that of the MUSE-2005 experiment, which has been investigated by Lemonsu et al. (2008). For MUSE-2006, problems may arise for southeasterly flow situations, which may include contribution to the turbulent fluxes from the Père-Marquette Park (see Fig. 1). Wind direction measurements indicate that this type of situation only occurred during days 83 and 87 , and the wind speed was less than $2 \mathrm{~m} \mathrm{~s}^{-1}$ in these cases.

The footprint for radiative measurements, on the other hand, is determined by the view angle of the measurement sensor, that is, about $150^{\circ}\left(170^{\circ}\right)$ for shortwave (longwave) radiation. It is centered over the nadir axis of the radiometer (Schmid 1997). In this study, the ground surface at the base of the tower is dominated by grass because 1) the tower is installed in a backyard and 2) exceptionally in this area, the two closest houses are separated with a yard.

\section{Control experiment}

The surface energy budget obtained every $30 \mathrm{~min}$ from days 82 to 87 with the model setup described in the previous section [referred to as the control simulation (CTRL)] is compared with observations in Fig. 2. Interestingly, measurements for this period show a residual term that is considerably larger than the sensible heat flux. Overall, the observed energy budget in Fig. 2 is similar to that presented in Lemonsu et al. (2008) for days without snow in MUSE-2005 (their Fig. 13). It can be noticed in Fig. 2 that the net radiation during the first four nights is larger than during the last three nights, most likely because of larger incoming longwave radiation (not shown). A comparison of mean values for both measurements and simulation outputs is reported in Table 4, with biases and root-mean-square errors (RMSE). Periods when $Q^{*}>0$ and $Q^{*}<0$ are considered separately. In a manner consistent with the literature, these two periods are hereinafter referred to as daytime and nighttime, respectively, even though a more correct criterion should be related to incident shortwave radiation at the surface $S \downarrow$.

Results from Fig. 2 and Table 4 indicate that the sensible heat flux $Q_{H}$ in CTRL is largely overpredicted, with a simulated mean value $59 \%$ larger than measurements. A significant bias of $61 \mathrm{~W} \mathrm{~m}^{-2}$ for the sensible heat flux is found during daytime, which largely 


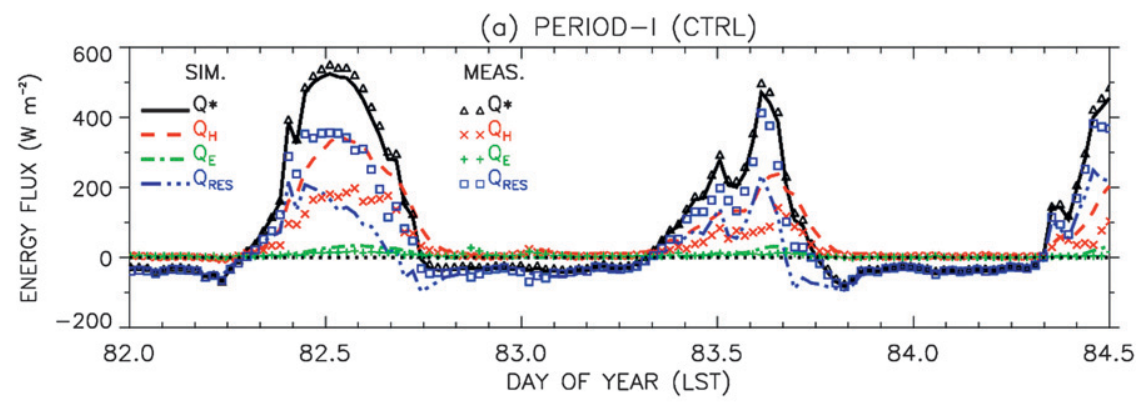

(b) PERIOD-II (CTRL)

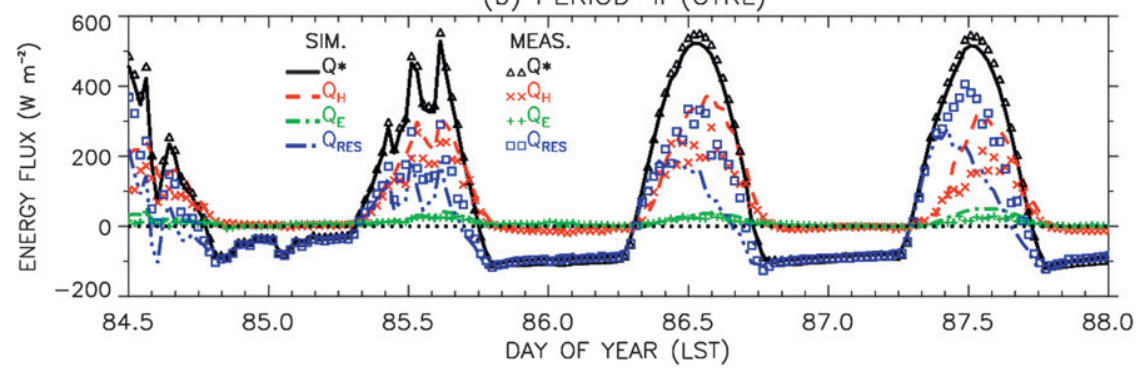

FIG. 2. Surface energy budget measured (symbols) and simulated (lines) obtained in the CTRL experiment: $Q^{*}$ is net radiation, $Q_{H}$ is sensible heat flux, $Q_{E}$ is latent heat flux, and $Q_{\text {res }}$ is the residual term: (a) PERIOD-I and (b) PERIOD-II.

contributes to an RMSE of $77 \mathrm{~W} \mathrm{~m}^{-2}$, in contrast to an RMSE of only $6.9 \mathrm{~W} \mathrm{~m}^{-2}$ during nighttime. This results in a large underestimation of the residual term, as it is determined from Eq. (3) for both measurements and simulation. Daytime RMSE for the residual term is about $105 \mathrm{~W} \mathrm{~m}^{-2}$; the value is $10 \mathrm{~W} \mathrm{~m}^{-2}$ at night.

The latent heat flux, on the other hand, is slightly overpredicted with a bias of $7 \mathrm{~W} \mathrm{~m}^{-2}$ and an RMSE of $12 \mathrm{~W} \mathrm{~m}^{-2}$ during daytime. This bias, however, is not observed during days 85 and 86 during which the simulated latent heat flux is in a fair agreement with measurements (Fig. 2b). The simulated net radiation $Q^{*}$ is slightly underestimated during daytime, with a bias of $-16 \mathrm{~W} \mathrm{~m}^{-2}$ and RMSE of $19 \mathrm{~W} \mathrm{~m}^{-2}$. As seen in Fig. 2, this behavior is observed each day. When considering separately the contributions from TEB and ISBA (not shown), results indicate that the $Q^{*}$ maxima from ISBA are smaller than the corresponding measurements whereas $Q^{*}$ maxima from TEB are closer to measured values (even though still underestimated). This is the case despite the fact that the radiative footprint area should be slightly more representative of natural surfaces than the urban surfaces, as mentioned in section 3. It thus seems that land surface processes are not correctly simulated over the natural surfaces.

The mean value of the residual term for the six days is about $36 \mathrm{~W} \mathrm{~m}^{-2}$ in the measurements, whereas it is close to zero in CTRL (Table 4). Clearly, the cause for this large energy excess is not taken into account by the model. Simple calculations indicate that the energy used for melting the sparse residual snowpacks and the anthropogenic fluxes from vehicle traffic release cannot explain this large discrepancy between model results and observations. One hypothesis is that this large residual term is associated with heat storage in the natural ground (i.e., related to latent heat required for thawing and freezing of soil water).

Surface temperature measurements on the natural ground in the ALLEY canyon seem to support this

TABLE 4. Mean values of the surface energy budget components from measurements (MEAS) and from the control simulation for all data, when $Q^{*}>0$ (i.e., daytime) and when $Q^{*}<0$ (i.e., nighttime), together with bias and $\operatorname{RMSE}\left(\mathrm{W} \mathrm{m}^{-2}\right)$.

\begin{tabular}{lrrrr}
\hline \hline & MEAS & CTRL & Bias & RMSE \\
\hline All data & & & & \\
$Q^{*}$ & 92.81 & 86.51 & -6.30 & 13.74 \\
$Q_{H}$ & 48.83 & 77.42 & +28.59 & 51.79 \\
$Q_{E}$ & 8.25 & 9.32 & +1.07 & 8.75 \\
$Q_{\text {res }}$ & 35.73 & -0.23 & -35.96 & 70.38 \\
$Q^{*}>0$ & $($ daytime $)$ & & & \\
$Q^{*}$ & 282.47 & 273.15 & -15.86 & 19.28 \\
$Q_{H}$ & 107.95 & 171.38 & +60.64 & 77.30 \\
$Q_{E}$ & 13.13 & 20.74 & +7.24 & 11.61 \\
$Q_{\text {res }}$ & 161.39 & 81.03 & -83.75 & 105.01 \\
$Q^{*}<0$ & $($ nighttime $)$ & & & \\
$Q^{*}$ & -58.92 & -56.62 & +1.34 & 6.52 \\
$Q_{H}$ & 1.54 & 5.30 & +2.94 & 6.90 \\
$Q_{E}$ & 4.34 & 0.57 & -3.86 & 5.46 \\
$Q_{\text {res }}$ & -64.8 & -62.55 & +2.26 & 9.66 \\
\hline
\end{tabular}




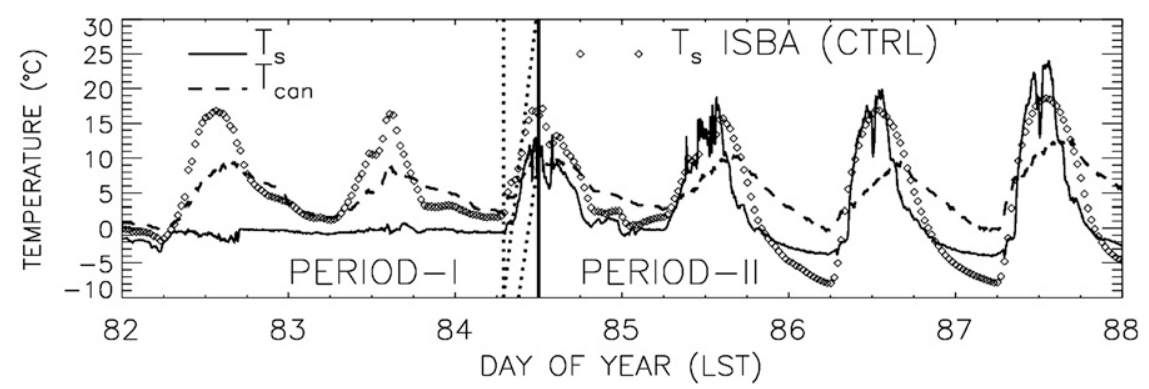

FIG. 3. Measurements of backyard surface temperature (solid line) and air temperature (dashed line) in the ALLEY canyon, and natural covers' surface temperature simulated in CTRL (diamonds). The hatched area corresponds to the transition between PERIOD-I and PERIOD-II.

hypothesis (Fig. 3), since they feature a plateau near $0^{\circ} \mathrm{C}$ for the first few days of the period, that is, until approximately the middle of day 84 (hereinafter PERIOD-I). For the following days (hereinafter PERIOD-II), this temperature exhibits a diurnal cycle of larger amplitude, with the maximum temperature increasing day by day. This behavior most likely corresponds to soil ice gradually thawing during PERIOD-I, which would be consistent with energy received on the natural surfaces being used for ice melting. It can be noticed that the measurements of the surface temperature (Fig. 3) exhibit fluctuations that may be due to the sensor (they are observed all along the experiment). Surface temperature simulated in CTRL for natural covers over the whole footprint area is represented in Fig. 3 for comparison, and is indeed overestimated during PERIOD-I. Note here that, in contrast, measurements are representative of a much smaller area.

The energy partitioning is quite different for the two periods, as shown in Table 5 for the mean daytime measured values of $Q_{H} / Q^{*}, Q_{E} / Q^{*}$, and $Q_{\text {res }} / Q^{*}$, that is, the energy components normalized by net radiation to avoid the influence of radiative forcing (note that here, averages are restricted to the interval 0800-1600 LST to avoid large ratios resulting from the division of small numbers near sunrise and sunset). The contribution of the sensible heat flux (and of the residual term) is larger (smaller) for PERIOD-II than for PERIOD-I. The contribution of the latent heat flux is also larger for PERIOD-II, but this flux still represents only a small part of the net radiation $(6 \%)$. The residual term plays a particularly important role in the energy distribution, as it represents $65 \%$ of the net radiation for PERIOD-I and $52 \%$ for PERIOD-II. Table 5 also shows that the Bowen ratio $Q_{H} / Q_{E}$ is large for both periods (with a value around 10). By comparison, Lemonsu et al. (2008) found that the energy budget for the snow-free period of MUSE-2005 was similar to that of PERIOD-II, with daytime respective contributions of $44 \%, 4 \%$, and $52 \%$ for sensible heat, latent heat, and residual fluxes. The Bowen ratio was also found to be close to 10 in their study.

The difference of situations during these two periods is confirmed when separating the mean residual term $Q_{\text {res }}$. For PERIOD-I, this term is 53 as opposed to $23 \mathrm{~W} \mathrm{~m}^{-2}$ for PERIOD-II (not shown), indicating that less energy is stored in the ground during PERIOD-II, and that there may be less (or no) ice thawing during PERIOD-II.

In summary, results from this section indicate that in the CTRL experiment the surface temperature is incorrectly simulated over natural surfaces (in particular for PERIOD-I) with an overestimation during daytime that likely resulted in the simulated overestimation of sensible heat flux. It is suggested that soil water melting and freezing may be responsible for this discrepancy between model results and observations. To improve the simulation of the urban SEB, several aspects of the modeling system were examined and tested, from geometric and thermal parameters of the urban fabric to physical processes represented in TEB and ISBA. Of all these tests, two aspects were found to be particularly important: soil freezing and thawing, and the parameterization of aerodynamic resistances in TEB that are crucial for the sensible heat flux computation. These two aspects are discussed in the next two sections.

TABLE 5. Mean measured values of surface energy budget partitioning and Bowen ratio during the daytime interval 08001600 LST.

\begin{tabular}{lcc}
\hline \hline & PERIOD-I & PERIOD-II \\
\hline$Q_{H} / Q^{*}$ & 0.31 & 0.42 \\
$Q_{E} / Q^{*}$ & 0.04 & 0.06 \\
$Q_{\mathrm{res}} / Q^{*}$ & 0.65 & 0.52 \\
$Q_{H} / Q_{E}$ & 9.64 & 11.39 \\
\hline
\end{tabular}




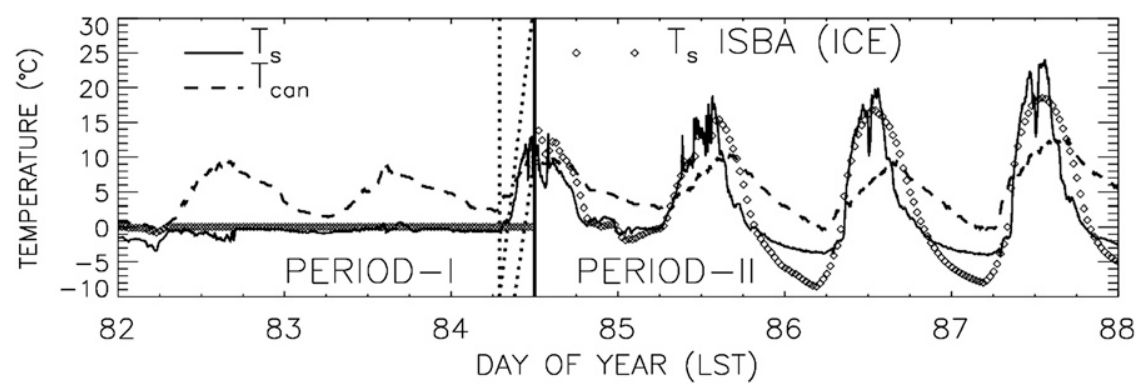

FIG. 4. As in Fig. 3, but with the surface temperature simulated in the ICE experiment (diamonds).

\section{Role of soil moisture freezing and thawing}

Considering that initialization of soil water content is quite challenging, particularly for its solid (ice) component, an additional run was performed to examine the sensitivity of the simulated surface energy budget to initial conditions of soil ice content.

To achieve this, the ISBA land surface scheme was first slightly modified to better represent the effect of soil freeze-thaw on the surface temperature. This modification consisted of the inclusion of an additional term in the prognostic equation for the surface temperature, which is then given by

$$
\begin{aligned}
\frac{d T_{s}^{\mathrm{nat}}}{d t}= & C^{\mathrm{nat}} G^{\mathrm{nat}}-\frac{2 \pi}{\tau}\left(T_{s}^{\mathrm{nat}}-T_{2}\right) \\
& +\frac{\rho_{w} L_{f}}{(\rho c)^{\text {soil }}} \frac{d W^{\text {freeze-melt }}}{d t}
\end{aligned}
$$

On the right-hand side of Eq. (4), the first term represents the heat stored into the natural surfaces (i.e., the forcing term), with $G^{\text {nat }}$ as the ground heat flux and $C^{\text {nat }}=\left[\left(f_{v} / C_{v}\right)+\left(1-f_{v}\right) / C_{g}\right]^{-1}$, where $C_{v}$ and $C_{g}$ are the heat capacity of vegetation and ground respectively, and $f_{v}$ is the proportion of vegetation on the natural surface. The second term represents a restoring process based on a mean soil temperature $\left(T_{2}\right)$, representative of a deeper layer in the soil, and on $\tau(24 \mathrm{~h})$, a characteristic time scale. The third term, added for this study, represents the latent heat absorbed or released because of water phase change, with $\rho_{w}$ as the density of water, $(\rho c)^{\text {soil }}$ as the volumetric heat capacity of the soil, $L_{f}$ as the latent heat of fusion, and $d W^{\text {freeze-melt }} / d t$ as the phase change of soil water, with positive values if soil is freezing and negative values if soil is thawing. This last term is bounded to ensure that $T_{s}^{\text {nat }}$ does not increase above $0^{\circ} \mathrm{C}$ when solid soil water is still available for melting.

Two simulations are examined for this sensitivity experiment. The differences between the control run and the new run termed ICE are listed hereinafter. In CTRL, the initial soil water is entirely liquid. In ICE, the initial conditions of soil ice were specified so that it completely melts by the end of PERIOD-I (i.e., at about the same time that measurements from the sensor in the backyard seem to indicate that all near-surface soil ice had melted; see Fig. 3). It should be noted that the initial equivalent water content is the same for the two cases, and that only the partitioning of soil water between liquid water and ice varies. In ICE (Fig. 4), during PERIOD-I, ice melts during daytime from about 0700 to 1600 LST, and water freezes during the night. During PERIOD-II, small amounts of frozen water appear again in ICE at about 0400 LST of days 86 and 87 because of lower air temperature (see ALLEY canyon air temperature in Fig. 4), but it has completely melted by 0800 LST. Figure 4 clearly shows that the new surface temperature simulated in ICE over the natural surfaces is in much better agreement with measurements in the backyard.

The surface energy budget for ICE is shown in Fig. 5 and can be compared with CTRL (Fig. 2). Evaluation against observations of the net radiation, the sensible heat flux, and the residual term shows some improvement in this case, as also confirmed by the RMSE computations shown in Fig. 6. It can be noted, however, that the sensible heat flux is still overestimated in ICE (Figs. 4a, 5a), in particular during daytime. Also, the simulated latent heat flux is near zero when ice is present in the soil, even though measurements exhibit small positive values. Different factors could explain these small values for observed latent heat fluxes: evaporation may occur somewhere in the footprint area where ice has melted previously, an anthropogenic moisture source may be present (traffic release), and sublimation of residual snowpacks may be expected. Net radiation is larger for ICE than for CTRL, in better agreement with measurements (Fig. 6a), because of lower surface temperature for the natural ground related to the presence of ice in the soil (see Fig. 4).

For PERIOD-II, results from CTRL and ICE display small differences (Figs. 2b, 4b) that can be more easily observed with the RMSE values (Fig. 6b). The slight 


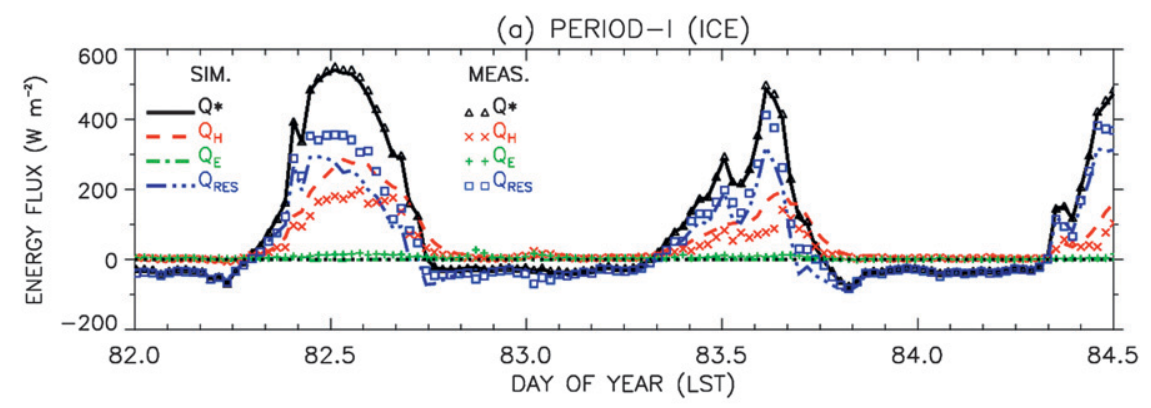

(b) PERIOD-II (ICE)

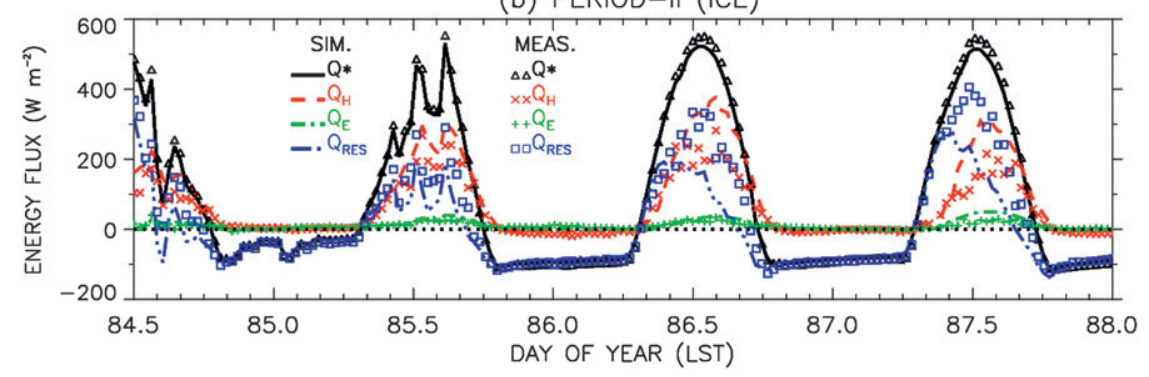

FIG. 5. As in Fig. 2, but simulated in the ICE experiment.

improvement observed is due in part to the lower natural ground surface temperature simulated in ICE at the beginning of PERIOD-II because the melting process during PERIOD-I has slowed down the natural ground heating. It is also due to the effect of water freeze/thaw that is observed in ICE between 0400 and 0800 LST of days 86 and 87 . Furthermore, the RMSE computed for ICE is larger during the daytime for PERIOD-II than for PERIOD-I (Fig. 6), with a value of about $70 \mathrm{~W} \mathrm{~m}^{-2}$ as compared with $50 \mathrm{~W} \mathrm{~m}^{-2}$ for the sensible heat flux and $95 \mathrm{~W} \mathrm{~m}^{-2}$ as compared with $50 \mathrm{~W} \mathrm{~m}^{-2}$ for the residual term.

Results thus indicate that the surface energy budget is sensitive to soil thawing, even if natural surfaces only represent $22 \%$ of the area. The soil ice melting process tends to largely decrease the sensible heat flux and increase the storage heat flux into the ground. Taking into account this physical process seems to be crucial for PERIOD-I. The experimental setup of the ICE run does not allow the significant improvement of the SEB partitioning computed for PERIOD-II. It can be noticed that the sensor used for measuring ground surface temperature (see Fig. 3) was located close to the southwestoriented wall (Table 1) and clearly received more solar energy than the other side of the ALLEY canyon. It is worth emphasizing, though, that this situation is not yet represented in the coupled TEB-ISBA, which does not consider interactions between built-up and natural surfaces. Therefore, the assumption made in the ICE experiment that no ice persists at the end of PERIOD-I needs to be reexamined.
It should be mentioned that even with the inclusion of soil thawing/freezing, the simulation results still show large daytime overprediction of the sensible heat flux and underestimation of the residual term, for almost all days, indicating that soil thawing is not responsible alone for the discrepancy between the control simulation and observations.

\section{Influence of aerodynamic resistances over built-up surfaces}

\section{a. Current approach and literature overview}

The evaluation of the current aerodynamic resistances network in TEB is made using Fig. 7, which compares observed and simulated net radiation on the main roof of the MUSE-2006 experiment. (Note that simulated results for this particular variable are the same for CTRL and ICE because no interactions between TEB and ISBA are represented in the offline system used in this study.) Although fair agreement is found between simulations and observations, Fig. 7 reveals that daytime maxima are overpredicted for several days.

This discrepancy between model results and observations has to be related to the way in which either solar or longwave net radiation is handled by the model. Because the albedo used for the roof is directly derived from measurements of downwelling and upwelling shortwave fluxes in clear sky conditions (see Table 3), it is unlikely that the overprediction of net radiation is caused by the solar component of the radiation budget. This suggests 


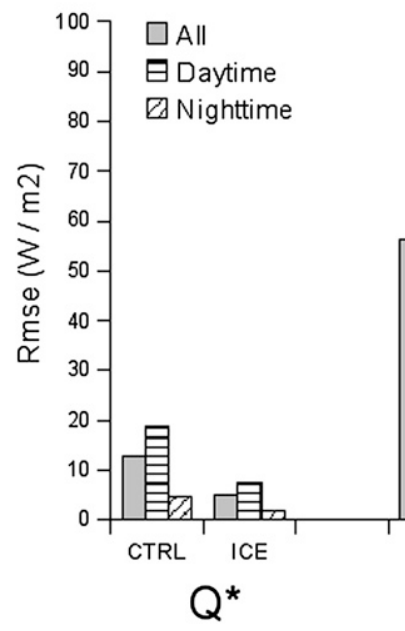

a) PERIOD-I

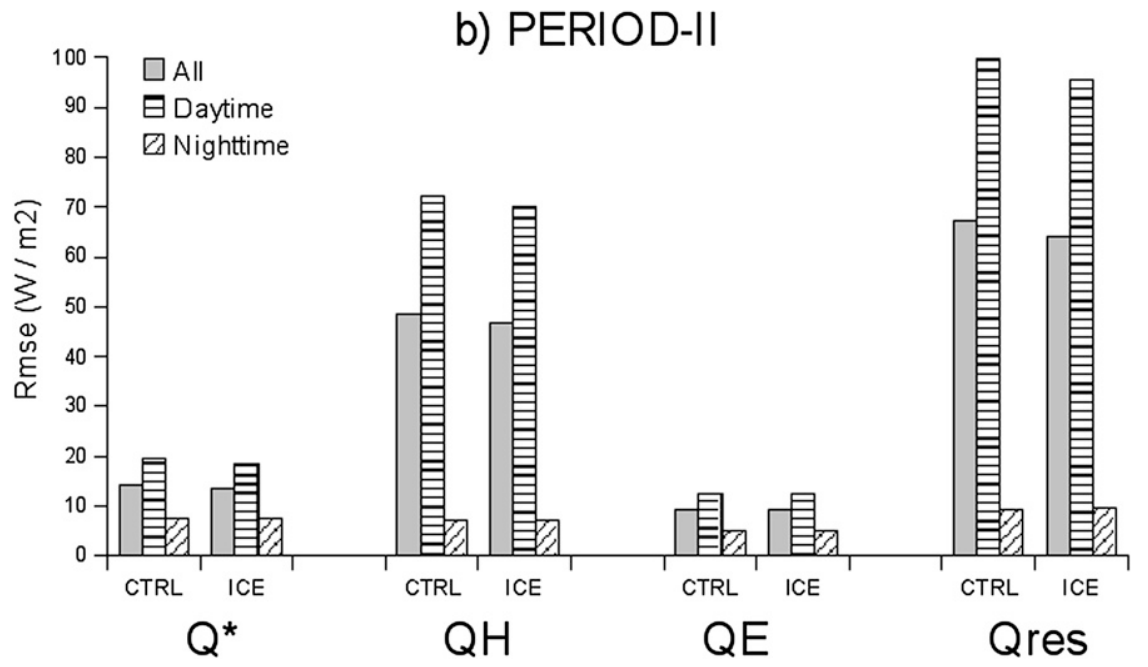

FIG. 6. RMSE calculated between surface energy budget components measured and simulated in the CTRL and ICE experiments: (a) PERIOD-I and (b) PERIOD-II.

that the net longwave radiation is overestimated by TEB, due to either an underprediction of roof surface temperature, or the prescribed values of the roof surface emissivity being too low.
It is not easy to determine whether the emissivity used in TEB is realistic or not for this particular roof. It is clear, however, that the roof surface temperature is underpredicted by TEB during daytime (see Fig. 8a),

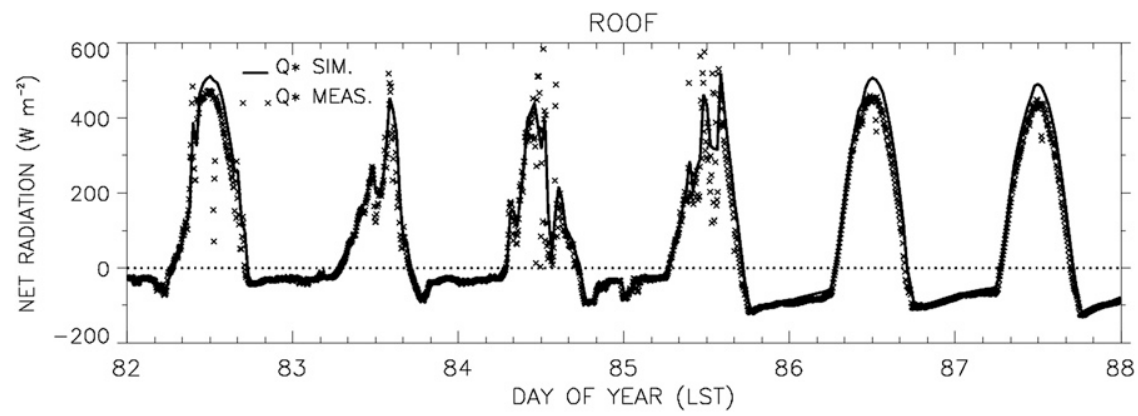

FIG. 7. Roof net radiation measured (symbols) and simulated (line) in the CTRL and ICE experiments. 
a)

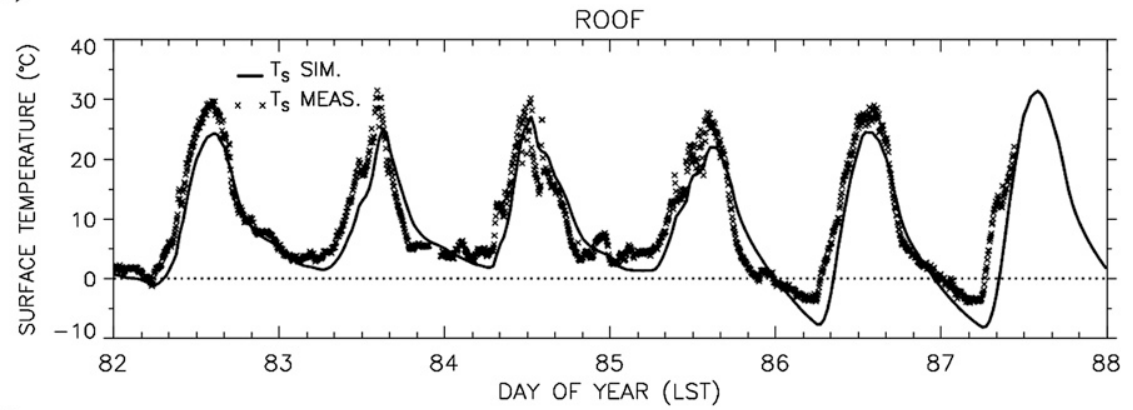

b)

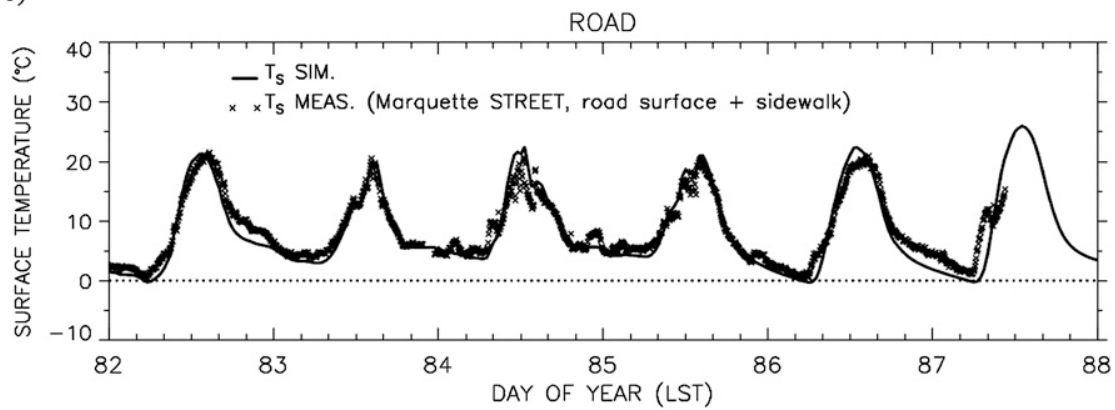

FIG. 8. Surface temperatures measured (symbols) and simulated (line) in the CTRL and ICE experiments on the (a) roof and (b) road surface type (including roads and sidewalks) in the STREET canyon. Measurements were not available after the middle of day 87.

even though the simulated surface temperature on the paved areas (i.e., on the road surface and on the sidewalks) in the STREET canyon compares well with measurements on Marquette Street (see Fig. 8b). Therefore, it is difficult to argue that the sensible heat fluxes are overestimated because of surface temperatures (which are in fact underestimated). This suggests another possible reason for the overestimation of $Q_{H}$, related to an underestimation of aerodynamic resistances used in the transfer equation.

Except for the walls, the aerodynamic resistances in TEB are computed using the roughness length for momentum $\left(z_{0 \mathrm{~m}}\right)$ and roughness lengths for heat and humidity ( $z_{0 \mathrm{~h}}$ and $z_{0 \mathrm{q}}$, considered equal) (Masson 2000; Masson et al. 2002; Lemonsu et al. 2004). Thermal and moisture roughness lengths are generally lower than the aerodynamic roughness length because the mechanisms involved in the transfer at the surface are not the same. Momentum transfer is mostly performed by pressure forces on the individual rough elements, whereas heat and scalar transfers are dominated by molecular diffusion.

The resistance between the air canyon and the air above is calculated in TEB using the same values for momentum and heat roughness lengths, because in this case, the transfer is not from a solid surface. The canyon is well ventilated and heat is easily exchanged between the canyon air and the atmosphere (Lemonsu et al.
2004). For the roof and road surfaces, the resistances in the control experiment are computed using a fixed ratio of $z_{0 \mathrm{~m}} / z_{0 \mathrm{~h}}=200$ representing the upper limit of the validity range of the analytical scheme of Mascart et al. (1995) used in TEB, which approximates the MOST equations. A fixed ratio is also considered in the ISBA land surface, with $z_{0 \mathrm{~m}} / z_{0 \mathrm{~h}}=5$.

Interestingly, the specification of $z_{0 \mathrm{~h}}$ depends on the definition of the surface temperature (Voogt and Grimmond 2000; Mahrt and Vickers 2004; Kanda et al. 2007). The aerodynamic surface temperature is relevant in the MOST framework, but it is difficult to measure (Trouffleau et al. 1997). Meteorological models generally use radiometric surface temperature instead, which is also used for the SEB and storage heat flux into the building and the deeper ground layers. As this solution tends to overestimate the sensible heat flux (Sun and Mahrt 1995), a specific formulation of $z_{0 \mathrm{~h}}$ is required (Sun and Mahrt 1995; Voogt and Grimmond 2000; Kanda et al. 2007; Baklanov et al. 2008).

This difference between momentum and heat roughness lengths is commonly expressed by $k B^{-1}=\ln \left(z_{0 \mathrm{~m}} /\right.$ $z_{0 \mathrm{~h}}$ ), where $k$ is the von Kármán constant and $B$ is the nondimensional sublayer Stanton number (Owen and Thomson 1963). Theoretical studies had suggested a dependence of $k B^{-1}$ on the roughness Reynolds number $\operatorname{Re}_{*}=\left(z_{0 \mathrm{~m}} u_{*}\right) / \nu$, where $u_{*}$ is the wind stress velocity 


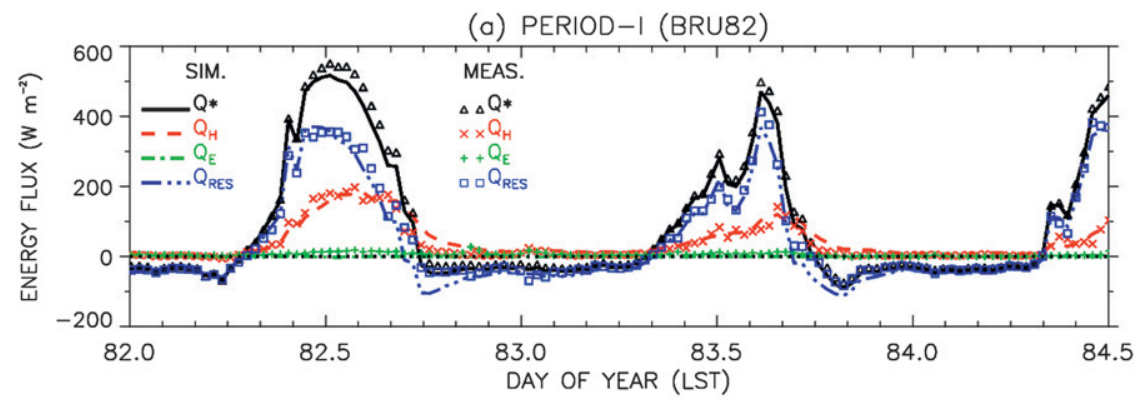

(b) PERIOD-II (BRU82)

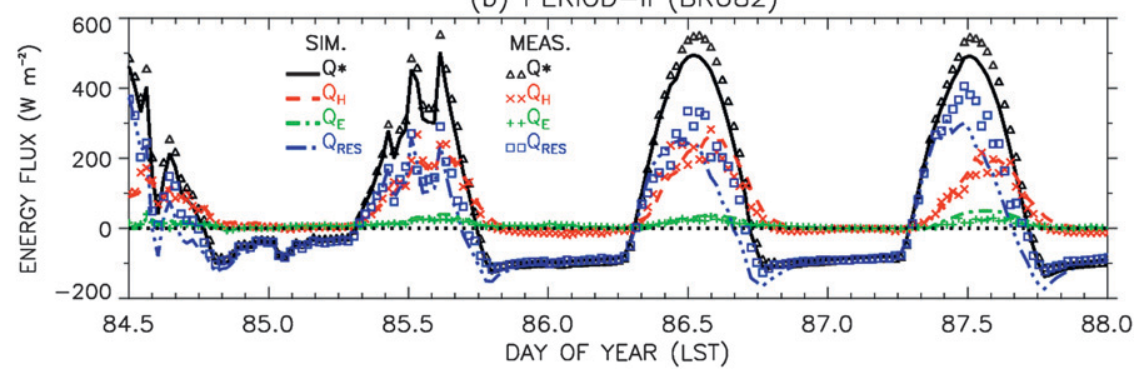

FIG. 9. As in Fig. 2, but simulated in the BRU82 experiment.

and $\nu$ is the air viscosity. Brutsaert (1982) determined a parameterization for rough bluff surfaces,

$$
k B^{-1}=a \operatorname{Re}_{*}^{0.25}-2,
$$

where $a=2.46$, as found using experimental data covering the range of $\mathrm{Re}_{*}<10^{3}$.

In a recent study, Kanda et al. (2007) compared this formula with long-term data obtained from urban-scale model experiments. Regression of their data covering a range of about $10<\mathrm{Re}_{*}<10^{4}$ gave $a=1.29 \mathrm{in} \mathrm{Eq.} \mathrm{(5),}$ and suggested lower values of $k B^{-1}$ than the original Brutsaert (1982) formulation. They compared also the results obtained from former experimental datasets conducted in urban areas over a Vancouver, Canada, light industrial district (Voogt and Grimmond 2000) and a Tokyo, Japan, dense residential district (Moriwaki and Kanda 2006) covering larger values of $\mathrm{Re}_{*}$. Particular attention is given here to the data obtained for the Vancouver district as the urban fabric likely has more similarities to the area presently studied (i.e., Vancouver and Montreal are both North American cities).

Values of $k B^{-1}$ found by Voogt and Grimmond (2000) were obtained from observed tower and modeled fluxes using a bulk heat transfer approach and different surface temperature estimations. The area of study had a very small vegetation fraction $(<5 \%)$. The results obtained were composed between the original Brutsaert (1982) model (largest values obtained) and the Kanda et al. (2007) regression (lowest values obtained) (see Fig. 6 of Kanda et al. 2007). It is difficult to link those experimental results of $k B^{-1}$ with the aerodynamic resistances network in TEB, as they are obtained considering the whole turbulent source area, including the various surfaces (e.g., walls, roads, and roofs). In contrast, the modification of the aerodynamic resistances in TEB may concern the local heat transfer on the roof and road horizontal surfaces only, as mentioned previously.

\section{b. Evaluation of Brutsaert (1982)}

In this study, the Brutsaert (1982) parameterization was implemented in TEB to calculate thermodynamic resistances for roof and road surface types. This experiment, referred to as BRU82, was conducted with the same initial conditions for soil ice as the ICE experiment, but using the new resistances network. The surface energy budgets simulated with BRU82 are shown in Fig. 9. The RMSE are plotted in Fig. 10, together with the results from the ICE experiment for comparison.

During PERIOD-I, BRU82 exhibits results in much better agreement with measurements (Fig. 9a) when compared with ICE (Fig. 5a). Lower values of the sensible heat flux are simulated, with daytime RMSE close to $22 \mathrm{~W} \mathrm{~m}^{-2}$ as compared with $52 \mathrm{~W} \mathrm{~m}^{-2}$ using the former parameterization (i.e., $z_{0 \mathrm{~m}} / z_{0 \mathrm{~h}}=200$; Fig. 10a). The residual term also fits the measurements better, with the daytime RMSE decreasing from about 50 to $32 \mathrm{~W} \mathrm{~m}^{-2}$. The partitioning between sensible heat flux and the residual term is now correctly simulated compared with measurements. The latent heat flux arises mostly from the natural surfaces and is therefore not affected by this 

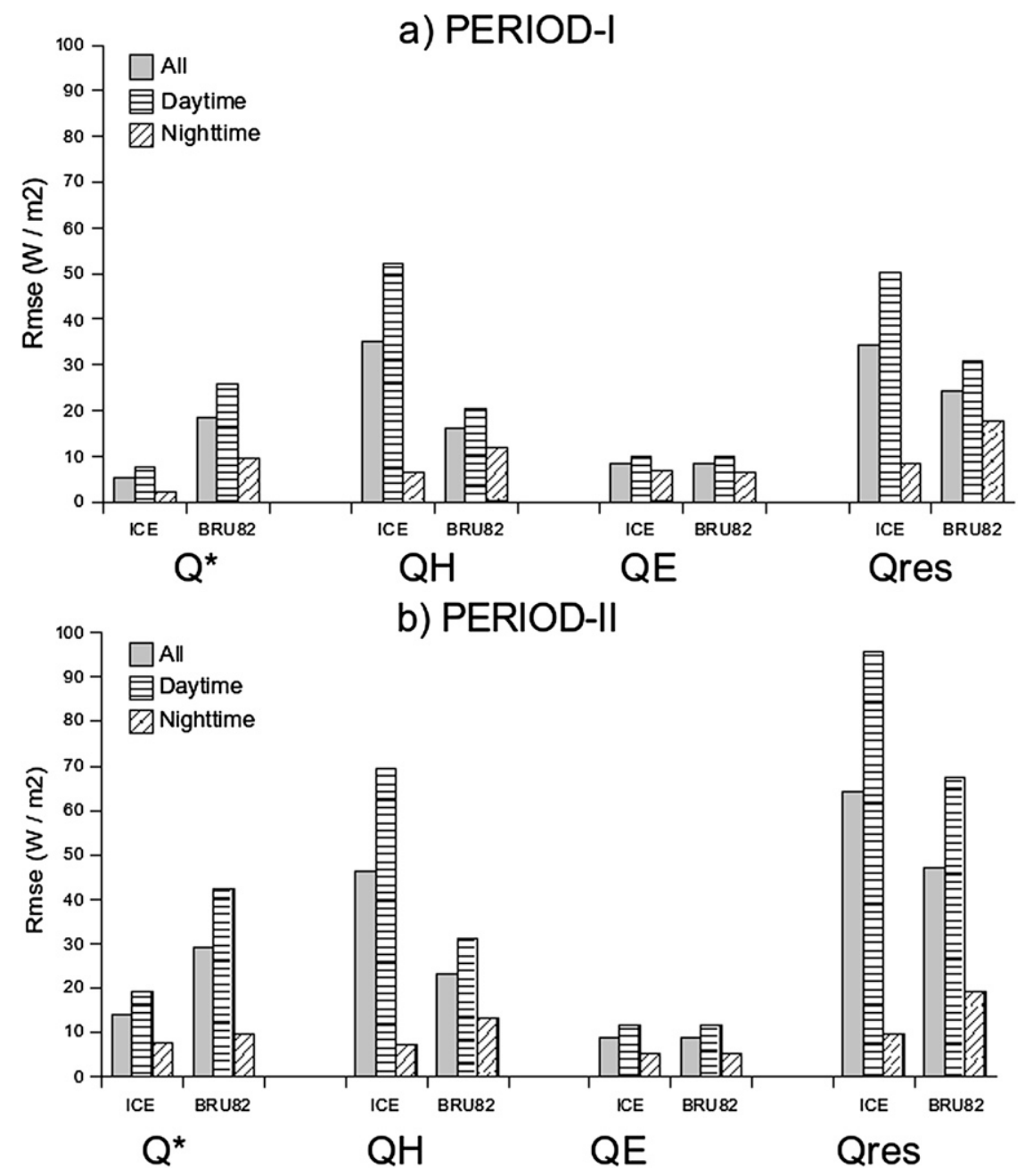

FIG. 10. RMSE calculated between surface energy budget components measured and simulated in the ICE and BRU82 experiments: (a) PERIOD-I and (b) PERIOD-II.

new parameterization (built-up surfaces are dry). The net radiation is decreased as surface temperature is increased on roofs and roads, because the aerodynamic resistances are larger. This leads to an increase in the RMSE values, from about 8 to $25 \mathrm{~W} \mathrm{~m}^{-2}$ for daytime. However, except for a slight underestimation after sunset, the net radiation maximum simulated on the roof now compares very well with measurements (Fig. 11), which suggests a correct estimation of the roof temperature. Moreover, $Q^{*}$ calculated on the natural surfaces with ISBA gives a maximum closer to measurements (not shown). It should be recalled here that the radiative

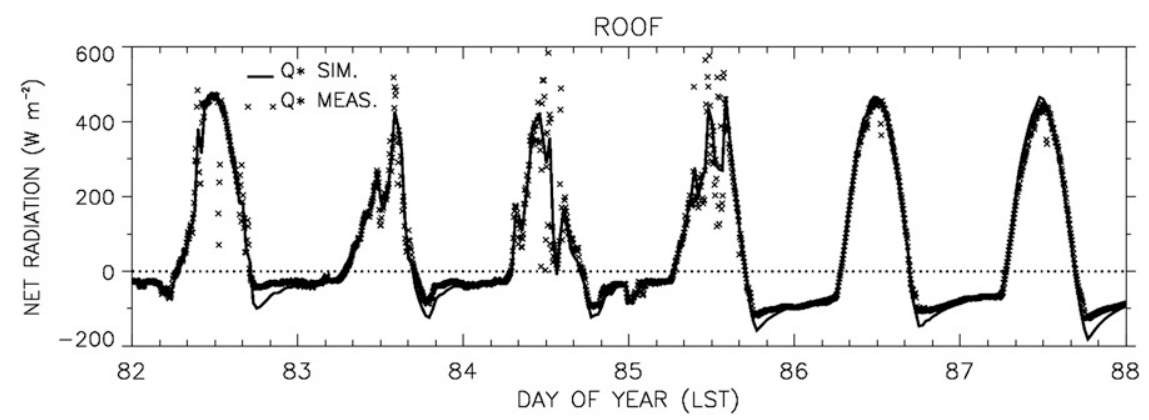

FIG. 11. As in Fig. 7, but simulated in the BRU82 experiment. 
sensors "see" more natural surfaces than urban covers for this area. Thus, this situation could partly explain the underestimation of $Q^{*}$ in the simulation.

For PERIOD-II, significant improvement is observed for the $Q_{H}$ simulation (Figs. 4b, 8b), with daytime RMSE of $70 \mathrm{~W} \mathrm{~m}^{-2}$ in ICE reduced to $30 \mathrm{~W} \mathrm{~m}^{-2}$ in BRU82 (Fig. 10b). The residual term is also better simulated, with daytime RMSE of about $95 \mathrm{~W} \mathrm{~m}^{-2}$ in ICE decreasing to $70 \mathrm{~W} \mathrm{~m}^{-2}$ in BRU82. It should be noted that a significant underestimation of $Q_{\text {res }}$ is observed after about 1100 LST for days 86 and 87 (Figs. 4b, $8 b)$. The latent heat flux is also in good agreement with measurements, except for day 87 when $Q_{E}$ is slightly overpredicted.

The results also indicate that the mean residual term simulated in BRU82 is about $40 \mathrm{~W} \mathrm{~m}^{-2}$ for PERIOD-I, whereas it is $53 \mathrm{~W} \mathrm{~m}^{-2}$ for the measurements (not shown). The difference of $13 \mathrm{~W} \mathrm{~m}^{-2}$ could be reasonably linked to the neglected terms (i.e., anthropogenic heat fluxes from traffic release and energy used for melting residual snowpacks). For PERIOD-II, however, the simulated value is about $-2 \mathrm{~W} \mathrm{~m}^{-2}$, although it is still $23 \mathrm{~W} \mathrm{~m}^{-2}$ for the measurements.

In summary, this section has shown the role of the thermal roughness length used over horizontal built-up surfaces in the urban surface energy budget partitioning. The inclusion of the Brutsaert (1982) model has significantly improved the results, for both periods. It should also be mentioned here that various tests with different parameterization of $k B^{-1}$ found in the literature did not provide better results than the ones presented in this section. For instance, results obtained with the regression by Kanda et al. (2007) still exhibit overestimation of the sensible heat flux even if the results are better than in the ICE simulation. Interestingly, the results obtained using the model of Zilitinkevich (1995), which depend on the root of $\mathrm{Re}_{*}$ and when setting the proportional constant to 0.7 or 0.8 [instead of the value 0.1 chosen by Chen et al. (1997) and Dupont and Mestayer (2006)] provide similar results than the model of Brutsaert (1982). These tests suggest the need to consider a relation that connects $k B^{-1}$ to $\mathrm{Re}_{*}$.

\section{Summary and conclusions}

The MUSE-2006 experiment dataset has been used to investigate the urban surface energy budget partitioning in a typical dense residential district of Montreal, at the end of winter during the period after snowmelt and before vegetation became active. The urban scheme TEB is used for the built-up fraction $(78 \%)$ while the land surface ISBA scheme is used for the natural surfaces $(22 \%)$. Stand-alone simulations had been conducted, considering both STREET and ALLEY canyons that characterize the district, for the last 6 days of the experiment during which the area was almost without snow cover. Meteorological forcing was provided by measurements taken at the top of a 20-m AGL tower.

Results from a control simulation reveal that the sensible heat flux is significantly overestimated when compared against observations, whereas the residual term obtained by closing the SEB is underestimated. The large positive values of the residual term from observations taken during the six days, together with the evolution of the surface temperature measured over the natural ground, suggest that ice was melting in the soil, a process not included in the offline modeling system. The analysis highlights two distinct periods, with more evidence of the influence of the soil ice thawing found during PERIOD-I than during PERIOD-II. The prognostic equation for the land surface temperature has been improved in ISBA to better account for the water phase change in the soil. The simulated energy budget is noticeably improved when ice melting is represented in the simulation, in particular for PERIOD-I.

This modification, however, is not sufficient to significantly improve the energy budget for both periods. Based on net radiation measurements on the roof, the assumption is made that the thermodynamic exchanges over roofs and roads are overestimated. Following previous theoretical and experimental studies, the parameterization of the roughness length for heat of Brutsaert (1982) has been introduced in TEB for roof and road aerodynamic resistances. This modification to TEB has significantly improved the RMSE values by about $50 \%-$ $55 \%$ for the sensible heat flux and by about $25 \%-30 \%$ for the residual term, for both periods.

There is some evidence that the ice freeze/thaw process is still not well represented during PERIOD-II in the BRU82 experiment, as suggested, for example, by the underestimation of the residual term for the last two days, by the values of the mean residual term that are underestimated, and by the overestimation of the latent heat during the last day. Nevertheless, a simulation with more initial soil ice was also tested (not shown in this paper), in which the freeze/thaw process continued during all of PERIOD-II; however, this caused the performance of the simulation to deteriorate.

This study has indicated that some improvements are necessary to the TEB and ISBA surface schemes to better represent the complex physical processes present in urban areas. Although we have achieved good success in better parameterizing these surfaces, several other modifications to these two schemes could lead to further improvements. For instance, a more direct inclusion of natural covers inside urban canyons and consideration 
of main street orientations would potentially allow the simulation of surface heterogeneity in early spring. This could also be very important during other seasons, when tree leaves may play an important role in the energy budget, an impact recently examined by Lee and Park (2008). Despite the good agreement found between measurements and model results with the new parameterizations of the soil freeze-thaw process and of the thermal roughness lengths over roads and roofs, uncertainties remain about these processes and further studies are still necessary. In particular, the possible underestimation of the observed turbulent fluxes, due to the eddy correlation technique used in MUSE, may have an impact on the interpretation of the results obtained in this paper, and may influence the choice of the parameterization for the thermal roughness length over builtup covers. Moreover, the use of these parameterizations should also be investigated for nonurban (i.e., natural) surfaces.

Acknowledgments. This research was funded by the Canadian Foundation for Climate and Atmospheric Sciences (CFCAS) within the framework of the Environmental Prediction in Canadian Cities (EPiCC) Research Network. The MUSE data were obtained through a Chemical, Radiological, Biological, and Nuclear (CRBN) Canadian Research and Technology Initiative (CRTI) grant held at the Meteorological Service of Canada (MSC). The authors thank all of the participants of the field experiment, and especially F. Chagnon for data supervision, quality treatment, and useful discussion.

\section{REFERENCES}

Arnfield, A. J., 2003: Two decades of urban climate research: A review of turbulence exchanges of energy and water, and the urban heat island. Int. J. Climatol., 23, 1-26.

Baklanov, A., P. G. Mestayer, A. Clappier, S. Zilitinkevich, S. Joffre, A. Mahura, and N. W. Nielsen, 2008: Towards improving the simulation of meteorological fields in urban areas through updated/advanced surface fluxes description. Atmos. Chem. Phys., 8, 523-543.

Baldocchi, D. D., 2003: Assessing the eddy covariance technique for evaluating carbon dioxide exchange rates of ecosystems: Past, present and future. Global Change Biol., 9, 479-492.

Bélair, S., L. P. Crevier, J. Mailhot, B. Bilodeau, and Y. Delage, 2003a: Operational implementation of the ISBA land surface scheme in the Canadian Regional Weather Forecast Model. Part I: Warm season results. J. Hydrometeor., 4, 352-370.

—, R. Brown, J. Mailhot, B. Bilodeau, and L. P. Crevier, 2003b: Operational implementation of the ISBA land surface scheme in the Canadian Regional Weather Forecast Model. Part II: Cold season results. J. Hydrometeor., 4, 371-386.

—, J. Mailhot, A. Lemonsu, M. Benjamin, F. Chagnon, G. Morneau, and R. Hogue, 2006: The Montréal Urban Snow
Experiments (MUSE). International Association for Urban Climate (IAUC) Newsletter, No. 16, 9-10. [Available online at http://www.urban-climate.org/IAUC016.pdf.]

Beyrich, F., and Coauthors, 2006: Area-averaged surface fluxes over the Litfass region based on eddy-covariance measurements. Bound.-Layer Meteor., 121, 33-65, doi:10.1007/s10546006-9052-x.

Brutsaert, W., 1982: Evaporation into the Atmosphere: Theory, History, and Applications. Reidel, 299 pp.

Chen, T. H., and Coauthors, 1997: Cabauw experimental results from the Project for Intercomparison of Land-Surface Parameterization Schemes. J. Climate, 10, 1194-1215.

De Ridder, K., and G. Schayes, 1997: The IAGL land surface model. J. Appl. Meteor., 36, 167-182.

Dupont, S., and P. G. Mestayer, 2006: Parameterization of the urban energy budget with the Submesoscale Soil Model (SM2U). J. Appl. Meteor. Climatol., 45, 1744-1765.

- T. Otte, and J. K. S. Ching, 2004: Simulation of meteorological fields within and above urban and rural canopies with a mesoscale model (MM5). Bound.-Layer Meteor., 113,111-158.

Foken, T., 2008: The energy balance closure problem: An overview. Ecol. Appl., 18, 1351-1367.

Grimmond, C. S. B., 2006: Progress in measuring and observing the urban atmosphere. Theor. Appl. Climatol., 84, 3-22, doi: 10.1007/s00704-005-0140-5.

, and T. M. Oke, 1995: Comparison of heat fluxes from summertime observations in the suburbs of four North American cities. J. Appl. Meteor., 34, 873-889.

$\ldots$, and — 1999a: Heat storage in urban areas: Local-scale observations and evaluation of a simple model. J. Appl. Meteor., 38, 922-940.

$\longrightarrow$, and _ 1999b: Aerodynamic properties of urban areas derived from analysis of surface form. J. Appl. Meteor., 38, 1262-1292.

Hamdi, R., and G. Schayes, 2007: Validation of an urban boundary layer scheme with measurements from two mid-latitude European cities. Atmos. Chem. Phys., 7, 4513-4526.

, and V. Masson, 2008: Inclusion of a drag approach in the Town Energy Balance (TEB) Scheme: Offline 1D evaluation in a street canyon. J. Appl. Meteor. Climatol., 47, 2627-2644.

Kanda, M., 2007: Progress in urban meteorology: A review. J. Meteor. Soc. Japan, 85B, 363-383.

—, A. Inagaki, M. O. Letzel, S. Raasch, and T. Watanabe, 2004: LES study of the energy imbalance problem with eddy covariance fluxes. Bound.-Layer Meteor., 110, 381-404.

—- M. Kanaga, T. Kawai, R. Moriwaki, and H. Sugawara, 2007: Roughness lengths for momentum and heat derived from outdoor urban scale models. J. Appl. Meteor. Climatol., 46, 1067-1079.

Kohsiek, W., C. Liebethal, T. Foken, R. Vogt, S. Oncley, C. Bernhofer, and H. Debruin, 2007: The Energy Balance Experiment EBEX-2000. Part III: Behaviour and quality of the radiation measurements. Bound.-Layer Meteor., 123, $55-75$.

Kondo, H., Y. Genchi, Y. Kikegawa, Y. Ohashi, H. Yoshikado, and H. Komiyama, 2005: Development of a multi-layer urban canopy model for the analysis of energy consumption in a big city: Structure of the urban canopy model and its basic performance. Bound.-Layer Meteor., 116 (3), 395-421.

Kusaka, H., H. Kondo, Y. Kikegawa, and F. Kimura, 2001: A simple single-layer urban canopy model for atmospheric models: Comparison with multi-layer and slab models. Bound.-Layer Meteor., 101, 329-358. 
Lee, S. H., and S.-U. Park, 2008: A vegetated urban canopy model for meteorological and environmental modelling. Bound.Layer Meteor., 126, 73-102.

Lemonsu, A., C. S. B. Grimmond, and V. Masson, 2004: Modeling the surface energy balance of the core of an old Mediterranean city: Marseille. J. Appl. Meteor., 43, 312-327.

— , and Coauthors, 2008: Overview and first results of the Montreal Urban Snow Experiment 2005. J. Appl. Meteor. Climatol., 47, 59-75.

_, S. Bélair, J. Mailhot, and S. Leroyer, 2010: Evaluation of the Town Energy Balance model in cold and snowy conditions during the Montreal Urban Snow Experiment 2005. J. Appl. Meteor. Climatol., in press.

Leroyer, S., I. Calmet, and P. G. Mestayer, 2010: Urban boundary layer simulations of sea-breeze over Marseille during the ESCOMPTE experiment. Int. J. Environ. Pollut., 40, 109-122.

Mahrt, L., and D. Vickers, 2004: Bulk formulation of the surface heat flux. Bound.-Layer Meteor., 110, 357-379.

Mailhot, J., S. Belair, A. Lemonsu, L. Tong, A. Leroux, N. Benbouta, and R. Hogue, 2006: Urban modeling at the Meteorological Service of Canada. International Association for Urban Climate (IAUC) Newsletter, No. 17, 13-16. [Available online at http://www.urban-climate.org/IAUC017.pdf.]

Martilli, A., A. Clappier, and M. W. Rotach, 2002: An urban surface exchange parameterization for mesoscale models. Bound.-Layer Meteor., 104, 261-304.

Mascart, P., J. Noilhan, and H. Giordani, 1995: A modified parameterization of flux-profile relationship in the surface layer using different roughness length values for heat and momentum. Bound.-Layer Meteor., 72, 331-344.

Masson, V., 2000: A physically based scheme for the urban energy budget in atmospheric models. Bound.-Layer Meteor., 94, 357-397.

— C. S. B. Grimmond, and T. R. Oke, 2002: Evaluation of the Town Energy Balance (TEB) scheme with direct measurements from dry districts in two cities. J. Appl. Meteor., 41, 1011-1025.

Mauder, M., C. Liebethal, M. Göckede, J.-P. Leps, F. Beyrich, and T. Foken, 2006: Processing and quality control of flux data during LITFASS-2003. Bound.-Layer Meteor., 121, 67-88.

Mestayer, P. G., and Coauthors, 2005: The urban boundary-layer field campaign in Marseille (UBL/CLU-ESCOMPTE): Set-up and first results. Bound.-Layer Meteor., 114, 315-365, doi: 10.1007/s10546-004-9241-4.

Moriwaki, R., and M. Kanda, 2004: Seasonal and diurnal fluxes of radiation, heat, water vapor, and carbon dioxide over a suburban area. J. Appl. Meteor., 43, 1700-1710.

— area. J. Meteor. Soc. Japan, 84, 1063-1071.

Noilhan, J., and S. Planton, 1989: A simple parameterization of land surface processes for meteorological models. Mon. Wea. Rev., 117, 536-549.
Offerle, B., P. Jonsson, I. Eliasson, and C. S. B. Grimmond, 2005: Urban modification of the surface energy balance in the West African Sahel: Ouagadougou, Burkina Faso. J. Climate, 18, 3983-3995.

- C. S. B. Grimmond, K. Fortuniak, K. Klysik, and T. R. Oke, 2006: Temporal variations in heat fluxes over a central European city centre. Theor. Appl. Climatol., 84, 103-115.

Oke, T. R., 1982: The energetic basis of the urban heat island. Quart. J. Roy. Meteor. Soc., 108, 1-24.

- , 2006: Towards better scientific communication in urban climate. Theor. Appl. Climatol., 84 (1-3), 179-190.

_ 2007: Siting and exposure of meteorological instruments at urban sites. Air Pollution Modeling and its Application XVII, C. Borrego and A.-L. Norman, Eds., Springer, 615-632.

-, R. A. Spronken-Smith, E. Jauregui, and C. S. B. Grimmond, 1999: The energy balance of central Mexico City during the dry season. Atmos. Environ., 33 (24-25), 3919-3930.

Owen, P. R., and W. R. Thomson, 1963: Heat transfer across rough surfaces. J. Fluid Mech., 15, 321-334.

Rotach, M. W., and Coauthors, 2005: BUBBLE-An Urban Boundary Layer Meteorology Project. Theor. Appl. Climatol., 81, 231-261.

Roth, M., 2000: Review of atmospheric turbulence over cities. Quart. J. Roy. Meteor. Soc., 126, 941-990.

Roulet, Y.-A., A. Martilli, M. W. Rotach, and A. Clappier, 2005: A validation of an urban surface exchange parameterization for mesoscale models-1D case in a street canyon. J. Appl. Meteor., 44, 1484-1498.

Schmid, H. P., 1997: Experimental design for flux measurements: Matching scales of observations and fluxes. Agric. For. Meteor., 87, 179-200.

, H. A. Cleugh, C. S. B. Grimmond, and T. R. Oke, 1991: Spatial variability of energy fluxes in suburban terrain. Bound.-Layer Meteor., 54, 249-276.

Sun, J., and L. Mahrt, 1995: Determination of surface fluxes from the surface radiative temperature. J. Atmos. Sci., 52, 10961106.

Trouffleau, D., J. P. Lhomme, B. Monteny, and A. Vidal, 1997: Sensible heat flux and radiometric surface temperature over sparse Sahelian vegetation. I. An experimental analysis of the $k B^{-1}$ parameter. J. Hydrol., 188-189, 815-838, doi:10.1016/ S0022-1694(96)03172-1.

Voogt, J. A., and T. R. Oke, 1997: Complete urban surface temperatures. J. Appl. Meteor., 36, 1117-1132.

— , and C. S. B. Grimmond, 2000: Modeling surface sensible heat flux using surface radiative temperatures in a simple urban area. J. Appl. Meteor., 39, 1679-1699.

Zilitinkevich, S. S., 1995: Non-local turbulent transport: Pollution dispersion aspects of coherent structure of convective flows. Air Pollution III, H. Power, N. Moussiopoulos, and C. A. Brebbia, Eds., Vol. 1, Air Pollution Theory and Simulation, Computational Mechanics Publications, 53-60. 